Int. J. Electrochem. Sci., 13 (2018) 9803 - 9815

International Journal of

ELECTROCHEMICAL

SCIENCE

www.electrochemsci.org

\title{
Synergistic Effects between Gemini Inhibitor and Thiourea/thiazole/pyridine as Corrosion Inhibitors on N80 Steel in Brine Solution with Saturated $\mathrm{CO}_{2}$
}

\author{
Fuqiang $\mathrm{Hu}^{1}$, Weiqiang Zhang ${ }^{1}$, Jun Tang ${ }^{2}$, Juan Xie ${ }^{2}$, Junlei Tang ${ }^{3}$, Jianpeng Mao ${ }^{4}, \mathrm{Hu} \mathrm{Wang}^{2, *}$ \\ ${ }^{1}$ CNOOC Changzhou EP Coating Co. Ltd., Changzhou 213016, China, China \\ ${ }^{2}$ School of Materials Science and Engineering, Southwest Petroleum University, Chengdu 610500, \\ China \\ ${ }^{3}$ College of Chemistry and Chemical Engineering, Southwest Petroleum University, Chengdu 610500, \\ China \\ ${ }^{4}$ Beijing BSS Corrosion Protection Industry Co., Ltd., Beijing 100029, China \\ *E-mail: senty78@126.com
}

doi: $10.20964 / 2018.10 .59$

Received: 22 May 2018 / Accepted: 20 July 2018 / Published: 1 September 2018

\begin{abstract}
Inhibition performances of gemini imidazoline inhibitor on $\mathrm{N} 80$ steel in a $\mathrm{CO}_{2}$-saturated brine solution have been researched using weight loss and electrochemical methods. The synergistic effects of gemini with other inhibitors have also carried out with chemical and electrochemical measurements. It is shown that the gemini inhibitor can inhibit corrosion effectively. Gemini inhibitor is anodic type. Gemini and other inhibitors exists apparent synergistic effect. The mixed inhibitors demonstrate excellent protection to $\mathrm{N} 80$ steel. The best formula of mixture inhibitors is presented, $10 \mathrm{mg} / \mathrm{L} \mathrm{gemini}$ $+2 \mathrm{mg} / \mathrm{L}$ thiourea $(\mathrm{TU})+5 \mathrm{mg} / \mathrm{L}$ thiazole $(\mathrm{TZ})+5 \mathrm{mg} / \mathrm{L}$ pyridine (PD). The synergistic mechanism of gemini with other inhibitors is also proposed.
\end{abstract}

Keywords: N80 steel, polarization curve, EIS, gemini corrosion inhibitor

\section{$\underline{\text { FULL TEXT }}$}

(C) 2018 The Authors. Published by ESG (www.electrochemsci.org). This article is an open access article distributed under the terms and conditions of the Creative Commons Attribution license (http://creativecommons.org/licenses/by/4.0/). 